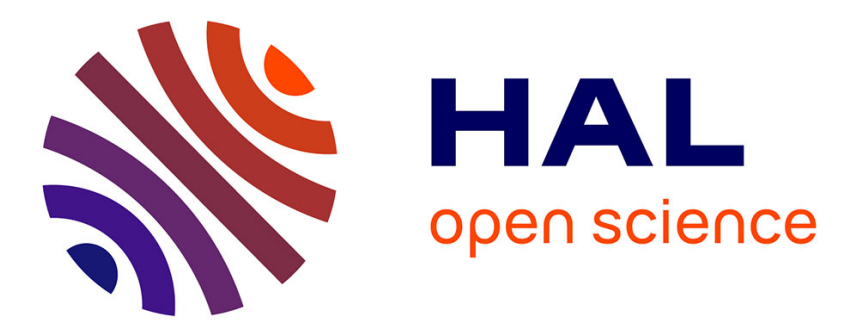

\title{
Assessment of epidemiological parameters and their use in epidemiological and forecasting models of cereal airborne diseases
}

Claude de Vallavieille-Pope, Simone Giosue, Lisa Munk, Adrian Newton, Rients Niks, Hanne Østergård, Jörn Pons-Kühnemann, Vittorio Rossi, Ivan Sache

\section{To cite this version:}

Claude de Vallavieille-Pope, Simone Giosue, Lisa Munk, Adrian Newton, Rients Niks, et al.. Assessment of epidemiological parameters and their use in epidemiological and forecasting models of cereal airborne diseases. Agronomie, 2000, 20 (7), pp.715-727. 10.1051/agro:2000171 . hal-00886079

\section{HAL Id: hal-00886079 https://hal.science/hal-00886079}

Submitted on 1 Jan 2000

HAL is a multi-disciplinary open access archive for the deposit and dissemination of scientific research documents, whether they are published or not. The documents may come from teaching and research institutions in France or abroad, or from public or private research centers.
L'archive ouverte pluridisciplinaire HAL, est destinée au dépôt et à la diffusion de documents scientifiques de niveau recherche, publiés ou non, émanant des établissements d'enseignement et de recherche français ou étrangers, des laboratoires publics ou privés. 


\title{
Assessment of epidemiological parameters and their use in epidemiological and forecasting models of cereal airborne diseases
}

\author{
Claude de Vallavieille-Pope ${ }^{\mathrm{a} *}$, Simone Giosue ${ }^{\mathrm{b}}$, Lisa MunK ${ }^{\mathrm{c}}$, Adrian C. Newton ${ }^{\mathrm{d}}$, \\ Rients E. NiKs ${ }^{\mathrm{e}}$, Hanne ØstergåRD ${ }^{\mathrm{f}}$, Jörn Pons-KÜHNEMANN ${ }^{\mathrm{g}}$, Vittorio Rossi ${ }^{\mathrm{b}}$, Ivan SACHE ${ }^{\mathrm{a}}$ \\ a INRA, Laboratoire de Pathologie Végétale et Epidémiologie, BP 01, 78850 Thiverval Grignon, France \\ ${ }^{\mathrm{b}}$ Istituto di Entomologia e Patologia vegetale, Università Cattolica S. Cuore, Via E. Parmense 84, 29100 Piacenza, Italy \\ ${ }^{c}$ Department of Plant Biology, The Royal Veterinary and Agricultural University, Thorvaldsensvej 40, \\ 1871 Frederiksberg C, Denmark \\ ${ }^{\mathrm{d}}$ Scottish Crop Research Institute, Invergowrie, Dundee, DD2 5DA, Scotland, UK \\ ${ }^{\mathrm{e}}$ Laboratory of Plant Breeding, PO Box 386, 6700 AJ Wageningen, The Netherlands \\ ${ }^{\mathrm{f}}$ Department of Plant Biology and Biogeochemistry, Ris $\varnothing$ National Laboratory, PO Box 49, 4000 Roskilde, Denmark \\ g Institut für Pflanzenbau und Pflanzenzüchtung II, Biometrie und Populationsgenetik, Justus-Liebig-Universität Giessen, \\ Heinrich-Buff-Ring 26-32, 35392 Giessen, Germany
}

(Received 10 May 2000; revised 7 July 2000; accepted 3 August 2000)

\begin{abstract}
Assessments of epidemiological parameters (e.g. infection efficiency, latent period, spore production) are required for the prediction of epidemic progress, for the estimation of components of partial resistance for different host plant cultivars and for the estimation of fitness components of pathogen isolates. A critical evaluation of methods of measurement of monocyclic parameters is presented, suggesting improvements by using more accurate techniques and taking into account different biotic and abiotic factors. Examples of influence of lesion density and age, of meteorological factors and of nutrient status of the host on cereal powdery mildew and rust epidemiological parameters are presented. The use of the ratio of mature lesions rather than the latent period for the estimation of the development rate of the fungus is suggested to allow comparison of a large number of individuals. It is feasible to assess the pathogen biomass by the sterol contents. The need to verify by field experiments epidemiological parameters assessed under controlled conditions is pointed out. Finally, the way to include these monocyclic parameters in epidemiological and forecasting models is discussed using the case of wheat brown rust epidemics.
\end{abstract}

infection efficiency / latent period / spore production / lesion density / microclimatic factors

Communicated by Hanne Østergård (Roskilde, Denmark)

* Correspondence and reprints

pope@grignon.inra.fr 
Résumé - Évaluation des paramètres épidémiologiques et leur utilisation dans les modèles de prévision des maladies foliaires des céréales. L'évaluation des paramètres épidémiologiques (efficacité d'infection, période de latence, taux de sporulation) est nécessaire à la prévision des épidémies ainsi qu'à l'estimation des composants de la résistance partielle des variétés hôtes et de la valeur sélective des isolats de l'agent pathogène. Une analyse critique des méthodes de mesure des paramètres du cycle infectieux est présentée avec des suggestions pour des techniques plus appropriées et la prise en compte de différents facteurs biotiques et abiotiques. L'influence de la densité et de l'âge des lésions, des facteurs microclimatiques et de l'état nutritionnel de l'hôte sur les paramètres épidémiologiques est étudiée à l'aide d'exemples chez les oïdiums et les rouilles des céréales. L'utilisation du taux de lésions matures plutôt que de la période de latence est conseillée pour comparer un grand nombre d'individus. Il est possible d'estimer la biomasse d'un parasite par la concentration en stérols. La nécessité de vérifier l'estimation des paramètres en conditions contrôlées et au champ est soulignée. Enfin, l'utilisation des paramètres épidémiologiques dans les modèles de prévision est discutée dans le cas de la rouille brune du blé.

efficacité d'infection / période de latence / sporulation / densité - dépendance / facteurs microclimatiques

\section{Introduction}

Whether a pathogen causes a significant epidemic is dependent upon the number of infection cycles it can complete in a normal host season. Such polycyclic diseases tend to be caused by pathogens capable of exponential increases in population size. The progress of such epidemics therefore depends on the actual values of the variables in each cycle from infection, incubation and lesion growth through to spore production which are specific for each combination of host genotype, pathogen genotype and environmental conditions. The understanding of cereal airborne diseases has been improved by quantification of monocyclic variables as influenced by external factors. Epidemiological parameter assessment is required for the prediction of epidemic progress, for the estimation of components of partial resistance for different host plant cultivars and for the estimation of fitness components of pathogen isolates.

One of the variables important for the rate of increase of an epidemic is the latent period of the pathogen. This is the period between the onset of spore germination and the appearance of the next spore generation. The shorter the latent period, the more reproduction cycles the fungus can realise per growing season. Simple simulation showed that a four-fold prolongation of the latent period from 4 to 16 days reduces the epidemic build-up much more than a four-fold reduction in the multiplication factor from 16 to 4 of the fungus [41].

For these polycyclic diseases, spore production is also a major factor for determining rates of disease progress. Knowledge of the effects of factors, such as lesion density and nutrient status of the plant, that may influence spore production is required for simulation of epidemics. The spore production from sporulating lesions influences the density of new infections established on the host tissue, together with the efficiency of spore dispersal and the infection efficiency, i.e. the proportion of deposited spores causing lesions [6]. When spore dispersal and landing are ignored, the multiplication factor (the product of spore production per lesion and infection efficiency) integrates these factors. The rate of disease progress in the host ('the apparent infection rate') can be shown in some cases to increase with the inverse of the latent period and with the Logarithm of the multiplication factor [36]. When the multiplication factor is low, then this factor may affect the epidemic rate more than the latent period.

Monocyclic experiments that cover only one infection cycle, from inoculation to subsequent sporulation, are usually performed in controlled conditions. The epidemiological variables (e.g. infection efficiency, latent period, spore production) are often expressed as a relative measure compared with that of an isolate on a well-known standard susceptible cultivar. Techniques used in 
monocyclic experiments are well known [14], however, using more accurate or more efficient measurements and taking into account more external factors can lead to progress. The aim of this paper is a critical evaluation of methods of measurement of epidemiological parameters examplified by published and unpublished studies on the four pathogens: Blumeria graminis (DC.) Speer f. sp. hordei (causal agent of barley powdery mildew), Puccinia striiformis Westend. (causal agent of wheat yellow (stripe) rust), Puccinia recondita Roberge ex Desmaz. f. sp. tritici (syn. P. triticina Eriks.) (causal agent of wheat brown (leaf) rust), and Puccinia hordei Otth. (causal agent of barley leaf rust). The first part concerns monocyclic components of the fungal infection cycle as influenced by biotic and meteorological factors and the nutrient status of the host. The second part shows how the assessed parameters are used in epidemiological and forecasting models. In the present paper, the term colony is used for powdery mildew, pustule for rust and lesion as a more generic term for both types of pathogen.

\section{Methodology for assessment of epidemiological variables}

\subsection{Effect of density and age of lesions on spore production and infection efficiency}

It is commonly observed that the variables of an infection cycle are density dependent. Infection efficiency, latent period and spore production have been reported to depend on inoculum and lesion density. High lesion density of mildew and rust increases growth of hyphae and reduces the latent period [e.g. 3, 17]. This negative relationship between inoculum density and latent period is not due to the fact that under high inoculum pressure the probability to detect some lesions early is higher than under opposing conditions, because the experiments were performed with fixed numbers of lesions which could be counted whatever the density was. Therefore differences in inoculum and lesion density may blur differences in quantitative resistance or parasitic fitness. The question is how to include the effect of pathogen density when estimating components of partial resistance and fitness parameters. Another factor seldom taken into consideration is the age distribution of lesions. This will influence the estimation of the multiplication factor, which declines as the pathogen ages or runs out of nutrients.

An experiment was designated to assess the effects of both pustule density and age on spore production and infection efficiency of brown rust under controlled conditions [35]. Spore production per pustule of an isolate of $P$. recondita f. sp. tritici was measured every 2 to 3 days during 30 days for a range of pustule densities: (9-76 pustules $\cdot \mathrm{cm}^{-2}$ ). Time was expressed as the number of days after inoculation. For all the studied densities, the first sporulating pustules were seen 7 days after inoculation. Spore production per pustule initially increased with time to a maximum, and later gradually decreased. When considered for a given collect day, spore production per pustule decreased exponentially with increasing pustule density when pustules were older than 13 days after inoculation. Conversely, crowding did not affect spore production of younger pustules. The negative effect of pustule crowding on their spore production per pustule has already been reported for black (stem) rust [16], barley leaf rust and wheat brown rust [4, 37], and explained by the competition for nutrients which occurs between pustules once they have reached a critical size.

In the same experimental conditions, infection efficiency was measured for three pustule densities: low (9 pustules $\cdot \mathrm{cm}^{-2}$ ), medium (30 pustules $\left.\cdot \mathrm{cm}^{-2}\right)$ and high $\left(73\right.$ pustules $\left.\cdot \mathrm{cm}^{-2}\right)$ and six ages ( 9 to 28 days) of the source pustule. Over the whole experiment, infection efficiency ranged from 0.15 to 0.35 . The most efficient spores were produced by medium-age pustules (14-21 days old) whatever their density was. Infection efficiency was much less affected by pustule ageing and crowding than was spore production.

Using these data, a mathematical expression was elaborated to relate the accumulated spore production to pustule age and density. The expression was used to evaluate spore production per pustule on a 
daily basis. The daily multiplication factor was higher at low pustule density. A slight increase in infection efficiency observed at high pustule density could not compensate for the reduced spore production. Similarly, in an experiment conducted with one isolate of $B$. graminis f. sp. hordei, colony density and spore production per colony were highly and negatively correlated $\left(\mathrm{r}=-0.88^{* * *}\right)$ [11]. This may contribute to a rapid increase in the numbers of sporulating lesions in cereal fields in the early stages of epidemics, which are usually initiated by a very low number of lesions. The age of powdery mildew colonies also affected the spore production. Spore production per colony during the period from 8 to 14 days after inoculation was measured on 6 barley cultivars. In general the youngest colonies (8-10 day old) produced a higher number of spores per colony per day than colonies being 12-14 day old [11].

In another study, infection efficiency and daily spore production over time were measured to assess the effect of inoculum and colony density on the effectiveness of partial resistance (corresponding to pathogen fitness). Mathematical growth models and non-linear regression were applied to estimate the respective parameters. An isolate of B. graminis f. sp. hordei taken from a Danish field was inoculated to four barley cultivars differing in their degree of partial resistance ( $\varnothing$ stergård, Damgaard and Tomiuk, to be published). Different kinds of interactions between fitness parameters were observed. Changes in inoculum density from 6 to 300 spores per $\mathrm{cm}^{2}$ influenced the infection efficiency of these spores differently on the four cultivars. Cultivars with high infection efficiency, i.e. the most susceptible, at low inoculum density, tended to show a low maximum number of colonies, i.e. being most resistant, at high inoculum density and vice versa. This potential effect of different resistance mechanisms should be investigated further. The spore production per colony per day throughout the period studied was higher at low $\left(3\right.$ colonies $\left.\cdot \mathrm{cm}^{-2}\right)$ than at high (12 colonies $\cdot \mathrm{cm}^{-2}$ ) colony density as expected, for all cultivars except one. Similarly, the time of maximum spore production was earlier at low density than at high density except for the same cultivar. It is suggested that the unexpected effect of colony density on spore production for this cultivar was caused by insufficient capacity of the partial resistance mechanism to control infections at high densities. In conclusion, the ranking of the four cultivars with respect to the two components of partial resistance changed with density.

Therefore, inoculum and lesion density should be taken into account when comparing cultivars for partial resistance and pathogen isolates for fitness, and when modelling disease progress. The change in spore production with lesion age seems to be less relevant for these purposes.

\subsection{Effect of microclimatic factors during the penetration phase}

Microclimatic conditions such as temperature, relative humidity, light intensity before and after inoculation of cereal plants may all greatly influence the reaction to powdery mildew and rust. Among the weather factors, moisture, particularly the duration of wetness, ranks as the dominant factor, followed by temperature [9]. The duration of surface wetness needed for germination and host penetration for each fungus depends on temperature. Free water on the leaf surface in the form of dew droplets (usually formed during the night) is essential for the germination of the rust spores [8]. Therefore, in working out the hours of wetness needed for infection of wheat brown and yellow rusts, the relationship to temperature has been established in controlled conditions and a model derived [40]. The minimum continuous dew period necessary for penetration, measured in controlled conditions, is $4-6 \mathrm{~h}$ for $P$. recondita f. sp. tritici and $P$. striiformis and increases to at least $16 \mathrm{~h}$ at suboptimal temperatures. An interruption of the wet period by a dry period does not affect ungerminated spores, which are able to infect during a subsequent wet period. Spores that have initiated the process of germination (sporelings) of $P$. recondita f. sp. tritici and $P$. striiformis are unable to survive if a dry period occurs between urediospore germination and penetration. However the two pathogens differ in their maximal infection 
efficiency under controlled conditions, the infection efficiency being 12 times greater for $P$. recondita f. sp. tritici than for P. striiformis. Recent field results contradicted the low infection efficiency $(<0.04)$ attributed so far to $P$. striiformis in controlled conditions. P. striiformis infection efficiency reached up to 0.40 in field conditions. The main difference between the controlled conditions and the field habitat is the deficient radiation in the controlled conditions. The effect of light intensity on infection efficiency was assessed by combining field and controlled environment data. Wheat seedlings grown in growth chambers and exposed to various regimes of light duration and intensity in both field and controlled conditions for $24 \mathrm{~h}$, were inoculated and incubated in growth chambers under optimal dew and temperature conditions (de Vallavieille-Pope, Huber, Leconte, Bethenod, unpublished data). Amount of light (light intensity $\times$ duration), both of daylight and of artificial light, prior to inoculation enhanced infection efficiency of wheat seedlings inoculated by $P$. striiformis. Infection efficiency ranged from 0.01 to 0.40 depending on the light amount. These results pointed out the need to verify by field experiments the epidemiological parameters assessed under controlled conditions. Field experiments helped identify those conditions in which $P$. striiformis had a high infection efficiency; growth chamber data supported the hypotheses.

Also for barley powdery mildew environmental conditions are important. As an example, infection efficiency can be reduced by over $50 \%$ at $7{ }^{\circ} \mathrm{C}$ compared with $20{ }^{\circ} \mathrm{C}$, although this varies with both barley genotype and mildew isolate [19]. Development rate, measured as the ratio of mature lesions (see below) depends in a similar way on temperature, again with barley genotype-dependent effects. The powdery mildew pathogen has a slower development rate (longer latent period, lower ratio of mature lesions) on $M l(L a)$ cultivars, for example, than on Mla7 cultivars [19]. This parameter also interacts with other microclimatic variables such as light [22].

\subsection{Comparison between assessment of latent period and ratio of mature lesions}

The latent period (LP) is important for describing epidemic development and assessing partial resistance [e.g. 1, 5] and is used in forecasting models. The development rate of a polycyclic epidemic is largely influenced by the LP duration, determining the number of infection cycles which can be completed during a season. LP is mainly influenced by temperature and level of susceptibility of the crop. For powdery mildew LP could be defined as the number of days to reach the final number of colonies [2], but LP is classically defined as the time interval between onset of the infection and maturation of the first lesion, or maturation of $50 \%$ of the lesions that will appear finally (LP50). A lesion is mature when it starts to release spores. Assessment of LP50 is time-consuming, since observations should be repeated every 12 or 24 h during several days. Alternatively, Newton [19] used the ratio of mature lesions (RML) which is the number of sporulating lesions observed when first visible to the naked eye relative to the final number of all surviving and sporulating lesions on the same leaves. The LP50 and ratio of mature lesions were compared for two pathogens on barley: P. hordei (Niks and Fernández, unpublished data) and $B$. graminis $\mathrm{f}$. sp. hordei [10]. The experiments were initially intended for two different purposes: one to compare barley progeny for partial resistance to leaf rust and the other to test the effect of nitrogen supply on barley powdery mildew.

The isolate 1.2.1 of P. hordei was inoculated to 103 recombinant inbred lines (RILs, $\mathrm{F}_{9}$ ) from the susceptible line L94 crossed with cv-Vada having partial resistance [32]. The latent period was measured in four series of experiments, with about 4 leaves per line per series. Pustules were counted daily. LP50 was calculated by interpolation between the measurement times immediately before and after the time at which $50 \%$ of the final number of pustules were mature. In two additional series of experiments, the ratio of mature lesions was determined. Mature pustules were counted twice: once when the majority of the pustules 
Table I. Statistics of relative latent period (LP50) and relative ratio of mature lesions (RML) of barley leaf rust isolate 1.2.1. on $103 \mathrm{~F}_{9}$ recombinant inbred lines (RILs) from the cross L94 $\times$ Vada. Relative LP50 is based on results of 4 experiments, relative RML of 2 experiments. Both are relative to the value measured on L94 (100\%); (Niks and Fernández, unpublished data).

\begin{tabular}{lcc}
\hline Property & $\begin{array}{c}\text { Relative } \\
\text { LP50 }\end{array}$ & $\begin{array}{c}\text { Relative } \\
\text { RML }\end{array}$ \\
\hline Most susceptible parent L94 & 100 & 100 \\
Most resistant parent Vada & 125 & 17 \\
Range of 103 RILs & $98.1-129.3$ & $134.5-5.5$ \\
Heritability (1) & $0.76^{(2)}$ & 0.87 \\
Coefficient of error variation (\%) & 5 & 28 \\
Correlation between relative & \multicolumn{2}{c}{-0.79} \\
LP50 and relative RML (r) & \multicolumn{2}{c}{-0.00}
\end{tabular}

(1) Ratio of the genetic variance (variance between RILs) and total variance.

(2) The heritability was corrected by dividing the error variance by two (two experiments), to allow direct comparison with the heritability of relative RML.

(3) Calculated as (square root of the $\mathrm{s}^{2}$ (within lines) divided by the average over all lines) $\times 100 \%$.

(about $80-90 \%$ of the final number of the pustules) were mature on the susceptible cultivar, and once when all the pustules were mature on all the lines. Both LP50 and RML were converted to values relative to those measured on the susceptible control L94 (Tab. I). The correlation between the relative ratio of mature lesions and the relative latent period was high $(\mathrm{r}=-0.79)$. The disadvantage of the relative RML is its relatively large coefficient of variation $(28 \%$ for relative RML to $5 \%$ for relative LP50). However, this disadvantage was counterbalanced by a higher heritability for the relative RML than for the relative LP50 (87\% versus 76\%). Of course, the relative RML depends quite strongly on the time of the first count (Fig. 1). A too early or too late time of assessment would lead to smaller differences between the barley lines. In the example depicted in Figure 1 the optimal time for the first count would be about 5.75 to 6 days after inoculation. Of course the time for assessment depends on the general development rate, which depends largely on microclimatic factors like temperature and on the stage of plant development.

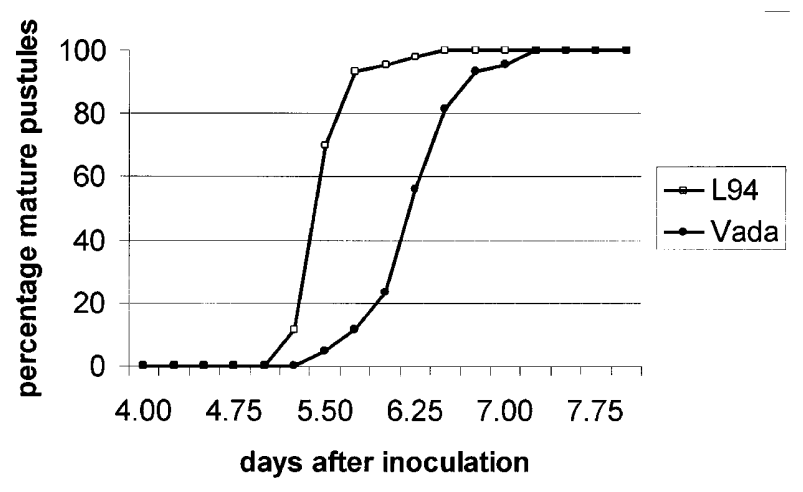

Figure 1. Increase of the proportion of mature pustules of barley leaf rust over time on a very susceptible barley line (L94) and partially resistant cultivar (Vada), illustrating that the difference in percentage of mature pustules between L94 and Vada depends on the time of observation (Niks and Fernández, unpublished data).

In the barley powdery mildew experiments, the number of colonies were counted from 5 to 10 days after inoculation of conidia of the $B$. graminis $\mathrm{f}$. $\mathrm{sp}$. hordei isolate $\mathrm{C} 15$ on seedling leaf segments of the cv-Pallas at $20^{\circ} \mathrm{C}$. RML was defined as the number of colonies six days after inoculation relative to the maximum number of colonies per leaf. The two components: latent period and RML were also highly correlated, $r=-0.84$ [10].

From the comparison between the two methods used to measure the development rate in the two pathosystems, it appeared that LP50 is laborious. Measurements of RML are less time-consuming especially if the lesion density is not too high. Niks and Fernández estimated a saving of about 35\% labour using RML compared with the LP50 measurements. As LP50 and RML are strongly correlated, RML appears to be an efficient alternative for measuring the development rate of the barley leaf rust and barley powdery mildew when screening plant material for improved partial resistance. However repeatability of RML between series seems lower than that of LP50. Another disadvantage of RML is that it does not fit into existing epidemiological simulation models. Nevertheless, it is worthwhile considering the feasibility of using RML in epidemiological models. 


\subsection{Other epidemiological parameter assessments}

Several epidemiological parameters can be combined in an index to allow global analyses. For example, the composite fitness index (CFI; [39]) which is similar to the multiplication factor mentioned above, calculated as the product of infection efficiency, colony size $\left(\mathrm{mm}^{2}\right)$ and spore production $\cdot \mathrm{mm}^{-2}$ colony surface, was compared for three B. graminis f. sp. hordei races that significantly differed in frequency in a powdery mildew field population [31]. The aim of the study was to find out whether differences in the CFI and the three variables on which it is based were responsible for the differences in frequency of the races. Whereas for the two less common races the CFI remains constant or was decreasing, the CFI of the most common race was increasing during the epidemic. This observation indicated a selection to higher aggressiveness for this race. In general none of the races differed in the same way for all of the variables. Correlation analysis of the CFI with single variables showed the highest correlation to the infection efficiency. In this study infection efficiency was also the most discriminating variable in the analysis of partial resistance of adult plants. A comparison of the epidemiological variables on leaves from the eighth leaf insertion with the cultivars Golden Promise and Villa showed the most pronounced effect on infection efficiency. Reduced infection efficiency was significant for cv-Villa in comparison to cv-Golden Promise, and for both cultivars in comparison to the response on their primary leaves. Differences in epidemiological variables for the three isolates, found on primary leaves, disappeared on the older leaves.

Some epidemiological parameters are a culmination of several others; for example, colony size and thereby overall mildew damage and spore production which will have a significant effect on plant yield. Assessment of the quantity of pathogen on and in the leaves is notoriously difficult. Visual assessments of the percentage of leaf covered by lesions is rapid, but quite subjective, and hence, not very reliable. The subjectivity of visual scores can be reduced by using objective assessment of total mildew biomass or biomass per colony which can be assessed using sterol cell-wall determination and enzyme-linked immunosorbent assay (ELISA) [22]. It quantifies the total amount of mildew mycelium which is present on the leaves. Polyclonal mildew antiserum reacted with barley leaves infected both under controlled and natural conditions [23]. There was no reaction with uninfected leaves, or with leaves of resistant cultivars exposed to mildew isolates. The reaction was approximately proportional to the level of mildew infection in naturally infected wheat, barley and oats. A barley cultivar known to express reduced colony size as a component of its partial resistance ('7204', Cornutum) gave reduced ELISA per colony values when it was used as a test cultivar in field experiments. Fungal biomass can also be assessed as fungal cell wall sterol content per colony. The reduced colony size of barley genotype '7204' was detected again [18] and shown to be environmentally sensitive in the reliability of its expression. The biomass per colony (assessed by sterol amount) was higher under low rather than under high infection frequency, as would be expected. However higher sterol content per colony was found in mixed isolate infections even at higher infection frequencies, indicating some synergystic interactions between heterogeneous mildew isolates. Sterol content per colony is a heritable component of resistance [20].

Image analysis has also been used to assess infection and was found to be as good as infection efficiency, but it was unable to detect the reduced colony size of cultivar 7204 found with the biochemical methods [20]. Similarly, image analysis was able to detect an effect of a seed treatment to control powdery mildew infection on winter barley which was not detectable on the basis of visual severity estimates [30]. However, this technique is more time consuming, requiring detached leaves, image analysis software and computers, camera and lighting hardware etc., whereas biochemical methods can utilise whole plant and detached leaf material but require destructive sampling.

Application of these techniques is generally limited by resources and thus some are best applied to the selection of breeding lines, whilst others are 
suitable for large scale screening. It is therefore important to know how one parameter correlates with another. For example, in mildew on barley, infection efficiency on seedlings is highly correlated with infection efficiency on adult plants and mildew biomass measurements made by ELISA from field sampled leaves. Mildew biomass measured on field samples is negatively correlated with mildew biomass per colony (ELISA) measured on adult plants in controlled environments, which in turn is negatively correlated with infection frequency on adult plants [24].

Colony or pustule numbers can be counted accurately on a small scale and in controlled environment tests, but generally measurements contain also a degree of subjectivity. These can be dealt with by careful use of keys that minimise differences between assessors [25]. However, we must also acknowledge the effects of environmental factors such as humidity and nutritional status which interact with host genotype and resistance expression $[21,26]$. We should be aware that infection with a pathogen in controlled environment conditions can be very different from the field environment where there are other organisms on the phylloplane. These other organisms are not always competitors or antagonists of infection, but may be a normal component of a successful pathogenic attack [27]. We should therefore always verify the epidemiological parameters of disease complexes in campo.

\subsection{Nutrient status}

Nutrient status of a plant may modify its susceptibility to disease. Nitrogen deficiency tends to retard the epidemic development of most foliar diseases like powdery mildew, brown and yellow rusts [e.g. 12, 29]. The reasons for the nitrogeninduced changes are not well understood, as only limited research has been performed on the influence of nitrogen on epidemiological parameters.

Experiments were designed to investigate the effects of nitrogen application on colony density and spore production of barley powdery mildew
[12]. The experiments were carried out under controlled conditions using attached first leaves of five or six barley cultivars and virulent powdery mildew isolates. Colony density increased significantly with increasing application of nitrogen on all cultivars. On three of the cultivars, the colony density increased for every application of nitrogen (30, 60, 120 and $240 \mathrm{mg} \mathrm{N}$ per pot), while on two of the tested cultivars, the colony density was unaffected at low or intermediate nitrogen levels. The interaction between nitrogen and cultivars was significant. It was shown that the differences could not be ascribed to differences in nitrogen uptake. The cumulative spore production per colony measured from 8 to 14 days after inoculation increased in most cases with nitrogen application, independently of colony density. Negative relationships between colony density and spore production per colony are commonly observed $[16,17]$, but as increased colony density due to increased nitrogen supply also coincides with increased spore production per colony, then $\mathrm{N}$ application can reverse the well-known relationship [12]. The cumulative spore production and nitrogen content of the plants were highly positively correlated, which indicates that nutrient availability is of major importance for spore production.

Under 'normal' inoculum conditions high levels of fertiliser can increase mildew area under the disease progress curve (AUDPC) five-fold, although the effect is less under high inoculum conditions [28]. There was no correlation between the amount of fertiliser, the level of mildew infection and yield loss. In a Danish two-year field study, increased nitrogen application increased susceptibility to barley powdery mildew and there was a linear relationship between powdery mildew severity and nitrogen rate. The estimated increase in powdery mildew was up to $4 \%$ per $40 \mathrm{~kg} \mathrm{~N} \cdot \mathrm{ha}^{-1}$ applied [10]. Split nitrogen-application delays powdery mildew development $[10,11]$. The main part of the effect of nitrogen fertilization in the field can be explained by the nitrogen-induced changes in infection efficiency and spore production. 


\section{Use of epidemiological parameters in dynamic disease modelling}

The quantification of monocyclic parameters of plant diseases and the effects of the external variables that influence them is a basic element in disease modelling. Every phase of the infection cycle can be modelled separately, from infection, incubation and lesion growth through to spore production and dispersal [7]. Such a model, generally referred to as simulation model, normally consists of two submodels, one of which models the behaviour of the pathogen and the other the host growth. Both are controlled by state and rate variables [15]. The interaction over time of the host and the pathogen, under the influence of environment, forms the epidemic. The environment itself is not part of the model, but affects both pathogen and host by external, 'driving' variables [7], like temperature, humidity, radiation, etc.

The model RustDEp (Rust Development of Epidemics) is a dynamic simulator of the daily progress of brown rust severity on wheat [34]. On any day, the proportion of leaf area that becomes infected depends on the spore production per pustule. This in turn is proportional to the sporulating pustule density on the leaf area, the proportion of susceptible leaf area free from infection and the infection rate (the proportion of spores able to establish new infections, INF). The infection rate depends on microclimatic conditions, particularly air temperature and leaf wetness. Infections develop into the leaf tissue without any visible symptom for some days, at a rate depending on temperature, until the day when the latent period (LP) is over; at which point they become visible as a proportion of leaf area occupied by pustules producing urediospores. Pustules produce spores for several days (the infectious period, IP); the rate at which the infectious period progresses over time depends on temperature and on the host growth stage. After the infectious period, the pustules become sterile as they age and the proportion of leaf area they occupy then ceases its participation in the epidemic. On any day, disease severity is then a sum of the leaf area covered by sporulating and no longer sporulating pustules.

Three driving models act in this conceptual model, i.e. the models calculating INF as influenced by the air temperature and leaf wetness [40], LP as influenced by the air temperature [13], and IP as influenced by the air temperature and the host growth stage [38]. It is possible to enlarge the simple main model by adding elements resulting from other experiments on epidemiological parameters. For instance, spore production accounting for pustule density could be added using data from the experiments of Sache [35].

Dynamic models make it possible to simulate what happens in the field under natural conditions, when all the driving variables are monitored and entered continuously into the model. In the RustDEp model, the input of meteorological data measured by a weather station allows an accurate simulation of the progress of brown rust severity on wheat [34]. Figure 2 shows an example of such a simulation, in the case of a brown rust epidemic developed on the flag leaf of the susceptible winter wheat cultivar Centauro at Piacenza (North Italy) in 1998. Meteorological data collected from a weather station placed in the neighbourhood of the crop were used as driving variables to calculate daily INF, LP and IP, whereas the leaf area was determined using the Wheat Growth Simulation model 'WheGroSim' [34]. The leaf area occupied by pustules was then obtained as the main model output. Disease severity was assessed in the field by comparing a sample of 100 randomly chosen leaves with a standard diagram [33], while the total leaf area was measured with a portable area meter on the same leaf sample. Comparison between actual and simulated data showed a very good agreement among model performances. In addition, the model was used to calculate the daily proportion of leaf area becoming infected, proportion of leaf area occupied by sporulating pustules, and the proportion of leaf area with pustules no longer sporulating. These intermediate model outputs allow a better understanding of the dynamics of the epidemic. 

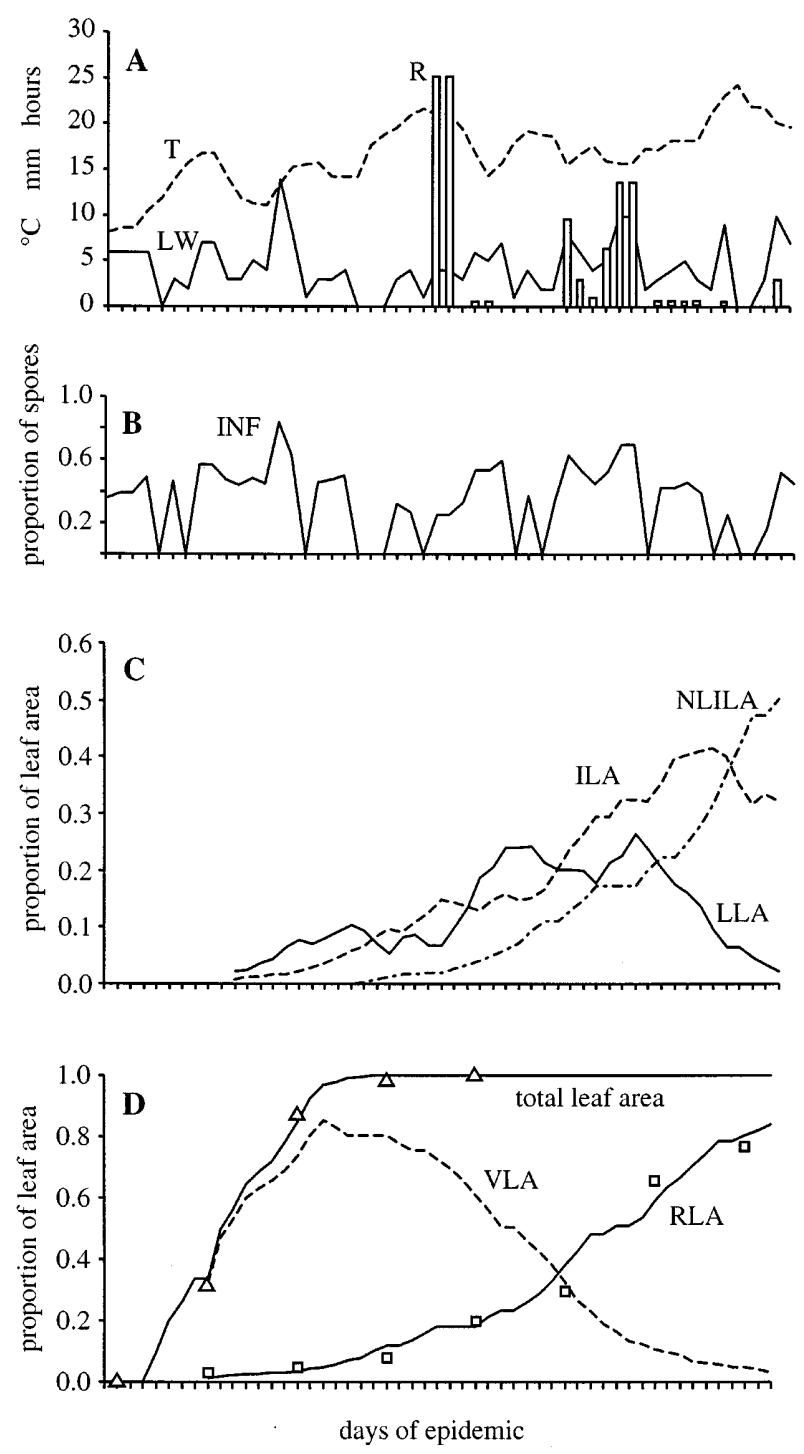

Figure 2. Example of the results obtained by operating the RustDEp model [34], using the data of mean temperature (T), rainfall (R) and leaf wetness (LW) measured at Piacenza (Italy), in 1998. Lines in the graphs B to D represent model calculations. INF is the proportion of spores that establish infection based on environmental conditions relative to the number that could have established infections under optimal conditions; LLA is the proportion of leaf area with latent infections, ILA is the proportion of total leaf area with sporulating pustules, NLILA is the proportion of leaf area with no longer sporulating pustules. VLA is the proportion of total leaf area that is vulnerable to infection (still green and infection free), RLA is the proportion of total leaf area with visible pustules. Points in the graph D represent actual values of the total leaf area $(\Delta)$ and the leaf area occupied by pustules of Puccinia recondita f. sp. tritici $(\square)$ assessed in the field.
The potential usefulness of dynamic models as forecasters depends particularly on the fact that they simulate the current status of each stage of the infection cycle and therefore contain information on the future status of any following stage. For instance, in a model like RustDEp, on any day during the epidemic the total amount of leaf area that will become rusted in the following 7 to 10 days (more precisely in a number of days equal to the latency) can be accurately calculated on the basis of the density of infections established on the previous days, being the leaf area with latent infections (LLA). An example of the accuracy of RustDEp in forecasting the future trend of disease progress is shown in Figure 3. The model was operated using meteorological data collected during a three-year period (1996-98) at 5 locations in Northern Italy, and the assessments of the disease severity were made weekly on the leaves of cvCentauro, as described previously. On each day i, forecasts of disease severity were produced for the day $\mathrm{j}(=\mathrm{i}+7)$ as a proportion of the leaf area with latent infections $\left(\operatorname{LLA}_{\mathrm{i}}\right)$; these forecasts were then compared with the actual disease severity on day $\mathrm{j}$. Comparison showed a good agreement between

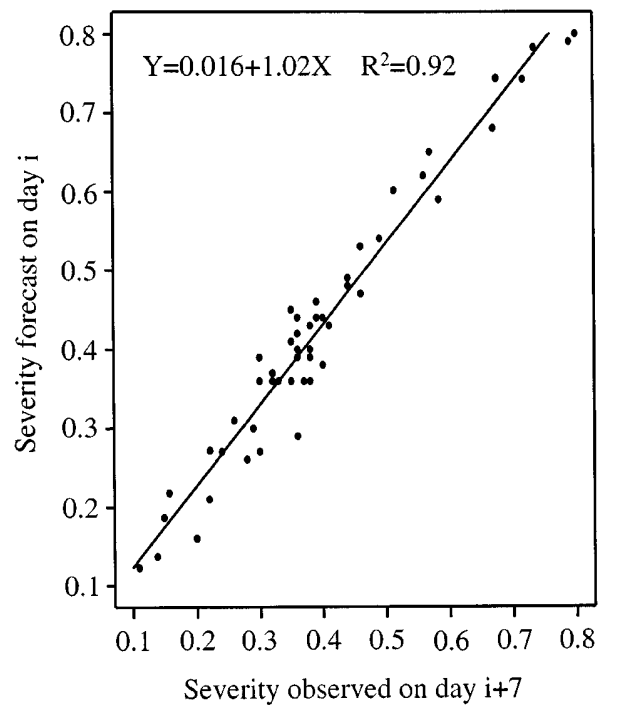

Figure 3. Comparison between the severity of Puccinia recondita f. sp. tritici (expressed as a proportion of the leaf area occupied by pustules) forecast on any day $i$, using the RustDEp model [34], and observed in the field on the day $i+7$. 
observed and forecast disease severity, the regression line between the two variables having an intercept not significantly different from zero and a slope not significantly different from one.

Unfortunately, although dynamic models are potentially useful in disease forecasting, they have seldom been employed for this purpose. Many of them are probably too complicated for practical use and efforts should be devoted to reducing both inputs and outputs. On the other hand the models could also be used to compare effectiveness of different components of partial resistance based on their contributions to reducing rates of disease increase. Plant breeders, who need to decide whether to try to increase levels of partial resistance in their new cultivars, may require more than simply comparisons between adjacent rows in breeding nurseries to convince them of the value of partial resistance. A dynamic model could be used to simulate disease development in fields of partially resistant cultivars relative to fields of a fully susceptible cultivar over a period of years for which adequate weather data are available.

\section{Concluding remarks}

The assessment of epidemiological parameters is fundamental to many applications of plant pathology and plant breeding. With the increasing exploitation of partial resistance, measurement of aggressiveness will have to be added to virulence analyses and more information on fitness components will be needed. Developing epidemiological prediction models also requires assessment of quantitative variables of the infection cycle. Such studies are conducted mainly at the population level. Because of the great number and complexity of the variables, this paper attempted to determine those parameters which are essential and how to use accurate tests given the large number of assessments needed. No single technique can assess the epidemiological parameters. Use of several techniques is advised, each providing complementary information. For example the development of standardised and simplified methods enables the quantification of latent period. Wall sterol content can provide an objective tool to assess pathogen biomass. Before studying more complex interactions, it is important to obtain estimates of the variables with the external factors controlled as much as possible. Furthermore, verification in field experiments of the relationships established under controlled conditions is imperative even if the relative ease of conducting experiments under controlled conditions makes it tempting to neglect the field.

Acknowledgements: This paper summarised studies conducted by members of two Working Groups of COST 817 on epidemiological parameters (working group managed by Claude de Vallavieille-Pope) and on partial resistance (working group managed by Rients Niks). It was written after the scientific exchanges during successive working groups in Risø (DK) in 1995, Lunteren (NL) in 1996, Giessen (D) in 1997, Praha (Czech Republic) in 1997, Edinburgh (UK) in 1998 and Martina Franca (I) in 1999. Tonnie Engels who initiated the working group on epidemiological parameters and Hanne Østergård who managed the COST 817 action are specially acknowledged.

\section{References}

[1] Alemayehu F., Parlevliet J.E., Variation between and within Ethiopian barley landraces, Euphytica 94 (1997) 183-189.

[2] Andersen L., Jørgensen J.H., Mlo aggressiveness of barley powdery mildew, Norweg. J. Agric. Sci. Suppl. 7 (1992) 77-87.

[3] Aust H.J., Kranz J., Einfluss der Konidiendichte auf Keimung, Infektion, Inkubationzeit und Sporulation bei dem echten Mehltau der Gerste (Erysiphe graminis DC. f.sp. hordei Marchal), Phytopathol. Z. 80 (1974) 41-53.

[4] Baart P.G.J., Parlevliet J.E., Limburg H., Effects of infection density on the size of barley and wheat leaf rust colonies before and on the size of uredia after the start of sporulation, J. Phytopathol. 131 (1991) 59-64.

[5] Broers L.H.M., Components of quantitative resistance to yellow rust in ten spring bread wheat cultivars and their relations with field assessments, Euphytica 96 (1997) 215-223. 
[6] Campbell C.L., Madden L.V., Introduction to plant disease epidemiology, J. Wiley and Sons, New York, 1990.

[7] Hau B., Modelling epidemics of polycyclic foliar diseases and development of simulators, in: Kranz J., Rotem J. (Eds.), Experimental techniques in plant disease epidemiology, Springer-Verlag, Berlin-HeidelbergNew-York, 1988, pp. 267-277.

[8] Hau B., de Vallavieille-Pope C., Wind-dispersed diseases, in: Gareth-Jones D. (Ed.), The epidemiology of plant diseases, Kluwer Academic Publishers, Dordrecht (The Netherlands), 1998, pp. 323-347.

[9] Huber L., Gillespie T.J., Modeling leaf wetness in relation to plant disease epidemiology, Annu. Rev. Phytopathol. 30 (1992) 553-577.

[10] Jensen B., Nitrogen induced changes in the development of barley powdery mildew, Ph.D. thesis from The Royal Veterinary and Agricultural University, Copenhagen, 1995, $111 \mathrm{p}$.

[11] Jensen B., Munk L., The effect of nitrogen application on resistance of barley to powdery mildew, Växtskyddsnotiser 57 (1993) 120-124.

[12] Jensen B., Munk L., Nitrogen-induced changes in colony density and spore production of Erysiphe graminis f.sp. hordei on seedlings of six spring barley cultivars, Plant Pathol. 46 (1997) 191-202.

[13] Johnson D.A., Effect of low temperature on the latent period of slow and fast rusting winter wheat genotypes, Plant Dis. 64 (1980) 1006-1008.

[14] Kranz J., Rotem J., Experimental techniques in plant disease epidemiology, Springer-Verlag, BerlinHeidelberg-New-York, 1988.

[15] Leffelaar P.A., Basic element of dynamic simulation, in: Leffelaar P.A. (Ed.), On Systems Analysis and Simulation of Ecological Processess, Kluwer Academic Publishers, Dordrecht, 1993, pp. 11-27.

[16] Leonard K.J., Factors affecting rates of stem rust increase in mixed plantings of susceptible and resistant oat varieties, Phytopathology 59 (1969) 1845-1850.

[17] Metha Y.R., Zadoks J.C., Uredospore production and sporulation period of Puccinia recondita $\mathrm{f}$. sp. triticina on primary leaves of wheat, Neth. J. Plant Pathol. 76 (1970) 267-276.

[18] Newton A.C., Measuring the sterol content of barley leaves infected with powdery mildew as a means of assessing partial resistance to Erysiphe graminis f.sp. hordei, Plant Pathol. 38 (1989) 534-540.
[19] Newton A.C., Genetic adaptation of Erysiphe graminis f.sp. hordei to barley with partial resistance, J. Phytopath. 126 (1989) 133-148.

[20] Newton A.C., Detection of components of partial resistance to mildew (Erysiphe graminis f.sp. hordei) incorporated into advanced breeding lines using measurement of fungal cell wall sterol, Plant Pathol. 39 (1990) 598-602.

[21] Newton A.C., The effect of humidity on expression of polygenic resistance to powdery mildew in barley, Plant Pathol. 42 (1993) 364-367.

[22] Newton A.C., McGurk L., Recurrent selection for adaptation of Erysiphe graminis f.sp. hordei to partial resistance and the effect on expression of partial resistance of barley, J. Phytopathol. 132 (1991) 328-338.

[23] Newton A.C., Reglinski T., An enzyme-linked immunosorbent assay for quantifying mildew biomass, J. Plant Dis. Prot. 100 (1993) 176-179.

[24] Newton A.C., Thomas W.T.B., Evaluation of sources of partial resistance to mildew in barley using enzyme linked immunosorbent assay and other assessment methods, Euphytica 66 (1993) 27-34.

[25] Newton A.C., Hackett C.A., Subjective components of mildew assessment on spring barley, Eur. J. Plant Pathol. 100 (1994) 395-412.

[26] Newton A.C., Guy D.C., Exploration and exploitation strategies of powdery mildew on barley cultivars with different levels of nutrients, Eur. J. Plant Pathol. 104 (1998) 829-833.

[27] Newton A.C., Toth I.K., Helper bacteria and pathogenicity assessments, New Phytol. 144 (1999) 385-386.

[28] Newton A.C., Guy D.C., Gaunt R.E., Thomas W.T.B., The effect of powdery mildew inoculum pressure and fertiliser level on disease tolerance in spring barley, J. Plant Dis. Prot. 107 (2000 ) 67-73.

[29] Oerke E.C., Schönbeck F., Effect of nitrogen and powdery mildew on the yield formation of two winter barley cultivars, J. Phytopath. 130 (1990) 55-61.

[30] Parker S.R., Shaw M.W., Royle D.J., The reliability of visual estimates of disease severity on cereal leaves, Plant Pathol. 44 (1995) 856-864.

[31] Pons J., Einfluß von Wirtsresistenz und Pflanzenalter auf die Fitness selektierter Pathotypen des Gerstenmehltaus Erysiphe graminis DC. f. sp. hordei Marchal, Diplomarbeit, Gießen, 1988.

[32] Qi X., Niks R.E., Stam P., Lindhout P., Identification of QTLs for partial resistance to leaf rust 
(Puccinia hordei) in barley, Theor. Appl. Genet. 96 (1998) 1205-1215.

[33] Rossi V., Manici L., Studio sulle caratteristiche di alcune scale di valutazione della gravità delle infezioni di ruggine bruna su frumento, Phytopathol. Mediterr. 29 (1990) 25-31.

[34] Rossi V., Racca P., Giosuè S., Pancaldi D., Alberti I., A simulation model for the development of brown rust epidemics in winter wheat, Eur. J. Plant Pathol. 103 (1997) 453-465.

[35] Sache I., Effect of density and age of lesions on sporulation capacity and infection efficiency in wheat leaf rust (Puccinia recondita f.sp. tritici), Plant Pathol. 46 (1997) 581-589.

[36] Shaw M.W., Pathogen population dynamics, in: Jones D.G. (Ed.), The Epidemiology of Plant Diseases, Kluwer Academic Publishers, Dordrecht (The Netherlands), 1998, pp. 161-180.

[37] Teng P.S., Close R.C., Effect of temperature and uredinium density on urediniospore production, latent period, and infectious period of Puccinia hordei Otth., N. Z. J. Agric. Res. 21 (1978) 287-296.

[38] Tomerlin J.R., Eversmeyer M.G., Kramer C.L., Browder L.E., Temperature and host effects on latent and infectious periods and on urediniospores production of Puccinia recondita f. sp. tritici, Phytopathology 73 (1983) 414-419.

[39] Tooley P.W., Sweigard J.A., Fry W.E., Fitness and virulence of Phytophthora infestans isolates from sexual and asexual populations, Phytopathology 76 (1986) 1209-1212.

[40] de Vallavieille-Pope C., Huber L., Leconte M., Goyeau H., Comparative effects of temperature and interrupted wet periods on germination, penetration, and infection of Puccinia recondita f.sp. tritici and P. striiformis urediniospores on wheat seedlings, Phytopathology 85 (1995) 409-415.

[41] Zadoks J.C., Modern concepts of disease resistance in cereals, in: Lupton F.G.H., Jenkins G., Johnson R. (Eds.), The way ahead in plant breeding, Proceedings of the sixth Eucarpia Congress, Cambridge, 1972, pp. 89-98. 